\title{
RECOOP Biopolymers and Cell
}

\section{Regional Cooperation for Health, Science and Technology (RECOOP HST) Consortium}

In 2006 Cedars-Sinai Medical Center (CSMC), Los Angeles, CA, USA with eleven Central and Eastern European (CEE) universities and academic organizations from six countries (Croatia, Czech Republic, Hungary, Romania, Slovak Republic, and Ukraine) formed the RECOOP HST Consortium.

The priority of the Consortium is to enhance research collaboration in CEE and to support scientific networking by means of common scientific and educational projects, Visegrad Scholarship and research grants.

The members of the RECOOP HST Consortium review periodically the scientific progress in the Consortium therefore organize the Bridges in Life Sciences Meetings. The first «Bridges in Life Sciences» Meeting was organized by CSMC before the formation of the Consortium in collaboration with Fogarty International Center, National Institute of Health (NIH) USA, and it was held in Budapest, Hungary in October 2003. That meeting highlighted US - CEE research collaborations in eight scientific tracks, providing an excellent networking opportunity for NIH-supported scientists from over ten CEE countries. The eight priority areas were: cancer, reproductive health, cardiovascular diseases, neurosciences, cell biology, functional genomics, proteomics, environmental health, and behavioral health sciences. The $2^{\text {nd }}$ «Bridges in Life Sciences» Annual Meeting was on October 5, 2007 in Pecs, Hungary, the $3^{\text {rd }}$ in Zagreb, Croatia on October 4, 2008, and the $4^{\text {th }}$ Meeting took place in Debrecen, Hungary on April 4-5, 2009. In Debrecen the Consortium provided opportunities for young scientists to discuss the major public health problems in the region and engage with senior scientists from the Consortium, the Visegrad Four (V4) Countries and with principal investigators of NIH funded research projects from the USA those had robust collaborative works in the CEE Countries. The $5^{\text {th }}$ Annual Scientific Meeting was organized not only for the RECOOP HST Consortium member organizations also for Universities and Research Institutes in Lviv, Ukraine on April 9-11, 2010.

The main activity of the RECOOP HST Consortium is research networking. The Consortium helps building multinational and multidisciplinary Research Networks to investigate complex diseases that are the major public health problems like women's and child's health, cardiovascular, neurodegenerative diseases, and cancer in CEE countries and worldwide.

The Consortium organized Support Networks also to disseminate best practice for Animal Care \& Use in Research, implement standard operating procedure (SOP) for Biosafety and Dual Use of Biotechnology, and provides management support for clinical research with the help of the Clinical Trial Site Management Network. The Consortium also offers training for faculty members, Ph.D students, young scientists, clinicians and managers to learn how to make decision on «publish and disclose» or «publish and protect» procedures. Therefore the Consortium established collaboration with the World Intellectual Property Organization (WIPO) and utilizes the World Wide Academy (WWA) Distance Learning (DL) courses. The Consortium also provides matching fund for Visegrad Scholarships and training for scientific communication, professional preparation of publications and grant writing (Grantsmenship).

The Biopolymers and Cell Journal's present issue will give an overview of the research activities in RECOOP HST Consortium.

«The RECOOP HST Consortium explores and enhances the LOCAL scientific outputs of the partner organizations, creates critical mass of scientifically sound innovative biotechnologies at the REGIONAL level and exploits the outcomes on the GLOBAL market.» ${ }^{\mathrm{TM}}$ 